\title{
Humic acids: Their detergent qualities and potential uses in pollution remediation
}

\author{
Ray von Wandruszka
}

Department of Chemistry, University of Idaho, Moscow ID 83844, USA

Article

Received 8th March 2000, Accepted 5th April 2000

Published on the Web 12th April 2000

Humic acids are amphiphilic species whose behavior in aqueous solution suggests that they form pseudomicelles - aggregates akin to the micelles familiar from synthetic surfactant chemistry. It is thought that humic pseudomicelles can be formed by both intramolecular coiling and intermolecular association, depending on the molecular weight, structural characteristics, and polydispersity of the humic acid in question. The process does not feature a critical micelle concentration. Experimental evidence indicates that metal ions enhance the detergent character of dissolved humic acid by facilitating the coiling and folding of the polymer chains. A recently conceived alternative model suggests that humic acids consist of relatively small subunits that associate through weak molecular interactions. This view appears to run counter to certain experimental observations, but deserves careful attention. The strong association between metal ions and solid humic acid makes it possible to use an inexpensive commercial grade for the decontamination of polluted water. A continuous elution process through a column packed with humic acid allows for the removal of both heavy metals and organic xenobiotics from aqueous solution.

\section{Introduction}

Humic substances are a ubiquitous depository of carbon in soil and natural waters. As the decay products of the total biota in the environment, they are highly refractory - mean residence times in soil vary from $c a .800$ to $>3000$ years. ${ }^{1}$ The humic substances found in soils, oceans, and deep lakes are generally autochthonous (produced within the system), while those in streams and shallow lakes are more often allochthonous (produced outside the system). Flowing surface and ground water are responsible for their distribution throughout the hydro- and lithosphere. They are formed through aerobic and anaerobic decomposition of (mostly) plant detritus, as well as secondary microbial synthesis. Differences in origin, age, and genesis lead to a high degree of chemical and morphological complexity that makes the compounds difficult to characterize. They generally have a high aromatic content, estimated (from ${ }^{13} \mathrm{C}$ NMR spectra) to range from 20 to $60 \%$ of the carbon present. $^{2}$ Heteroatomic functionalities include phenols and other alcohols, ketones/quinones, aldehydes, carboxylic acids amino- and nitro-groups, and sulfur containing entities such as mercaptans, sulfates, and sulfonates.

The diversity among humic substances makes their classification difficult. It is customary to divide them into three operationally defined classes, broadly based on their solubility characteristics. Thus humin is the fraction that is insoluble in both acid and base, humic acid (HA) is the fraction soluble at $\mathrm{pH} 2,{ }^{3}$ and fulvic acid (FA) is soluble at all $\mathrm{pH}$ values. Since the focus of this review is on dissolved humic substances, humin will not be considered here; emphasis will be given to HA. The relative quantities of the three fractions present in soil depend on the type of soil considered: in a typical mollisol the distribution is roughly equal, while humin prevails in vertisol, and FA in spodosol B. ${ }^{3}$ Humic deposits such as those found in association with leonardite (vide infra) consists almost entirely of HA. In aqueous media, FA is, for obvious reasons, generally more plentiful.

The differences in solubility between FA and HA are necessarily based on chemical differences. While the two classes of compounds share many structural features, including an abundance of carboxy, hydroxy, phenolic, and ketonic groups, FA has a lower molecular weight, a higher functional group density, and higher acidity than HA. Molecular weights for FA are in the 500-2000 Da range, while they extend from 2.0 to $1300 \mathrm{kDa}$ for HA. The oxygen content is reported as 32.8 $38.3 \%$ for HA, and $39.7-49.8 \%{ }^{4}$ for FA.

\section{Discussion}

A variety of texts give excellent accounts of the present state of knowledge regarding the structure, distribution, and chemical properties of HAs. ${ }^{5-12}$ One of the central issues in their study is the interaction with xenobiotics in the subsurface environment The importance of this lies in the fact that humics associate strongly with organic and inorganic compounds in soil and water, acting as both storage and transport agents for these species. The interaction of HA with metal ions, for instance, is extensive, and is based on the formation of strong metalhumate complexes. This topic has been reviewed thoroughly by Senesi, ${ }^{13}$ and will not be further elaborated here. In view of its relevance to subsequent issues, however, it should be noted that interactions vary with regard to the type of cation considered. Group I cations ("hard" ions) are likely to undergo electrostatic interactions with HA functional groups, while the bonds formed by "soft" Group III cations are more covalent in character. Group II cations, including $\mathrm{Cu}^{2+}, \mathrm{Fe}^{2+}, \mathrm{Co}^{2+}, \mathrm{Zn}^{2+}$, $\mathrm{Pb}^{2+}$, and $\mathrm{Ni}^{2+}$, behave in an intermediate fashion.

The interactions of HAs with organic compounds have been the subject of intensive study for several decades. This is especially true for sorptive processes involving the partition of organic solutes between aqueous and soil organic phases. Results are generally correlated with octanol-water partition coefficients $\left(K_{\text {ow }}\right)$ and have been described with reasonable success by the Flory-Huggins ${ }^{14}$ and the modified FloryHuggins theory. ${ }^{15}$ The UNIFAC method, which predicts activity coefficients based on group contributions, ${ }^{16}$ has also been applied to determine equilibria involving nonionic solutes and humic matter in soil. ${ }^{17}$ The interactions between hydrophobic solutes and dissolved humic matter (DHM) have been 
given somewhat less attention. The focus in this area has largely been on common organic pollutants, such as polycyclic aromatic hydrocarbons (PAHs), and a variety of biocides. Early results suggested that associations of PAHs with DHM are both rapid and reversible, and probably affect the binding of these contaminants to sediments. ${ }^{18}$ Work with nonionic pesticides indicated that hydrophobicity is not the only factor governing their interactions with DHM, and that, moreover, associations are not entirely reversible. ${ }^{19}$ In the case of HA, it was also noted that the origin of the material played a major role, and it was suggested that the extent of coiling of HA polymer strands is an important factor in their complex formation with nonionic organics. ${ }^{20}$

\section{Humic micelles}

The mechanism of interaction between dissolved HAs and nonionic organic compounds (especially nonpolar ones) continues to be subject to some controversy. It is, however, clear that these interactions are largely predicated on the detergent character of HAs. It is generally recognized that these materials are surface active and can solubilize a wide variety of hydrophobic species. A view that is presently widely accepted holds that this is due to a micelle-like organization in HA polymers in aqueous solution. The concept was introduced in a fundamental form by Rochus and Sipos in 1978, ${ }^{21}$ and was subsequently elaborated and refined by Wershaw, ${ }^{22-24}$ who established the present mode of thinking on the subject. The essence of the theory is that the HA amphiphile consists of an elongated hydrophobic portion with one or more anionic (carboxylate) groups attached at the end. These entities aggregate in the manner of synthetic surfactants, forming micellar or membrane-like structures (Fig. 1).

In work dealing with conventional humic micelles, the HA concentrations used have generally been in the $\mathrm{mg} \mathrm{mL}^{-1}(\mathrm{ppt})$ range. These high concentrations produce intensely colored (brown to black) solutions that are virtually opaque, making the application of many spectroscopic techniques impossible Moreover, such concentrated solutions rarely correspond to environmental situations. Most natural waters contain dissolved humic materials, but these are usually present at low ppm levels, imparting a faint yellow to brown color to the solution. It is therefore of practical interest to consider the detergent qualities and related mechanisms for HA solutions in the concentration range 5-100 ppm.

\section{Pseudomicelles}

Aqueous solutions of synthetic surfactants have a characteristic concentration known as the critical micelle concentration

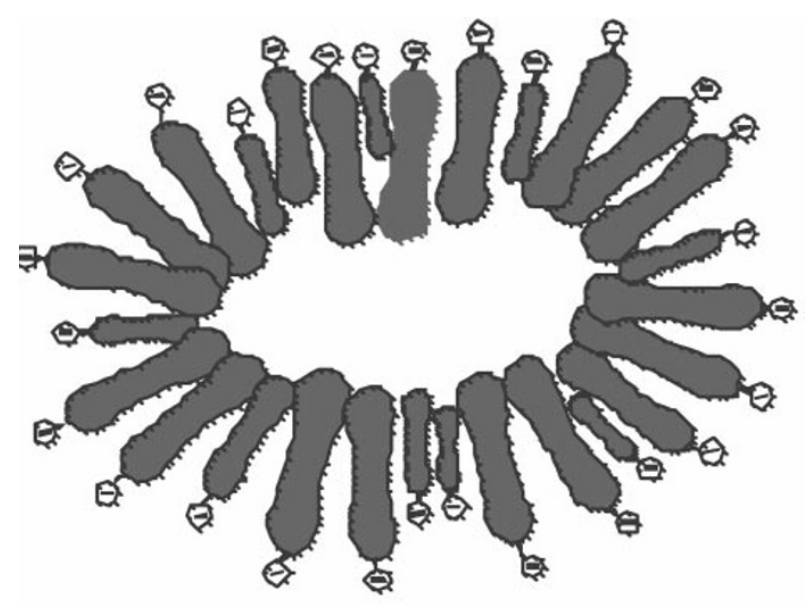

Fig. 1 Representation of humic micelle (adapted from ref. 22, with permission). (c.m.c.), at which the monomers spontaneously aggregate to form micellar assemblies. The same has been reported for the concentrated HA solutions mentioned above, which have estimated c.m.c. values as high as $10 \mathrm{~g} \mathrm{~L}^{-1} \cdot{ }^{25}$ For dilute HA solutions, however, Engebretson et al. found evidence for micelle-like organization which does not feature a c.m.c. ${ }^{26,27}$ In this model, the amphiphilic HA molecules are considered to "aggregate" both intra- and intermolecularly. The former is made possible by the chain length and flexibility of the humic polymers, which allow them to fold and coil in a manner that directs hydrophilic (e.g. carboxy and hydroxy) groups outward and keeps more hydrophobic (e.g. hydrocarbon) moieties isolated in the center. This process, which could in principle occur with a single polymer strand, produces an entity that is operationally similar to a conventional micelle, albeit more structurally constrained. Like a micelle, it has a hydrophobic interior and a more hydrophilic surface, giving it distinct solubilizing powers for nonpolar solutes. To indicate both similarities and differences with normal surfactant micelles, these HA structures have ben referred to as pseudomicelles. A portion of a generalized structure, which may be visualized as a "knot" in a HA polymer "string" is shown in Fig. 2.

Spectroscopic evidence for the existence of humic pseudomicelles has recently been reviewed by von Wandruszka. ${ }^{28}$ The structures are considered to exist at all low HA concentrations in aqueous solution, although certain variations in composition must be anticipated. It is, for instance, likely that intermolecular aggregation supplements intramolecular coiling in pseudomicelle formation, and that this depends on both the concentration and polydispersity of the solute. The proposed assembly thus consists of coiled humic polymer chains, interspersed with smaller HA fragments.

Fluorescence measurements of hydrophobic probes (e.g. pyrene) sequestered by the pseudomicelles indicate that this type of configuration affords the best isolation for these molecules. It is, for instance, clear that they are not accessible to solution borne fluorescence quenchers such as the bromide ion. ${ }^{26}$ When the size of the HA polymers was reduced by photolysis prior to the measurements, they lost their ability to micellize probe molecules, proving that short fragments alone are insufficient to form effective pseudomicelles. ${ }^{29}$ Similar deductions could be made regarding the nature of the humic material used. High pressure size exclusion chromatography and light scattering measurements showed that molecular size distributions vary widely among different $\mathrm{HAs}^{30}$. Likewise, some HAs (e.g. lignite derived) have a condensed aromatic backbone, which makes the polymer chains relatively rigid. In contrast, some soil HAs contain extensive alkyl linkages that lead to a flexible structure. It was found that long, supple HA polymers are considerably better sequestration agents for smal organic molecules than are short, rigid ones. This observation is consistent with the pseudomicellar model proposed above, since the flexible chains can coil more effectively.

Supporting evidence for this representation of HA is also provided by $3 \mathrm{D}$ modeling studies carried out by Schulten and Schnitzer. ${ }^{31,32}$ Using semiempirical calculations and known chemical features of HAs, they arrived at a set of open structures containing numerous voids (Fig. 3). While these models are valid only for pure compounds, they indicate that individual HA polymers can assume configurations that incorporate all the essential attributes envisaged for the pseudomicellar arrangement. Other modeling studies ${ }^{33,34}$ have used relatively small monomer units, such as the Steelink structure $^{4}$ (Fig. 4), to assemble HA polymers. Calculations on oligomers of this type suggested the formation of an HA helix with an $8.9 \AA$ pitch and potentially charged functional groups (carboxylate, phenolic, amine) distributed along the outside in a repeating pattern. The interior of the helix contained more hydrophobic groups, again establishing micelle-like nature of the assembly. 


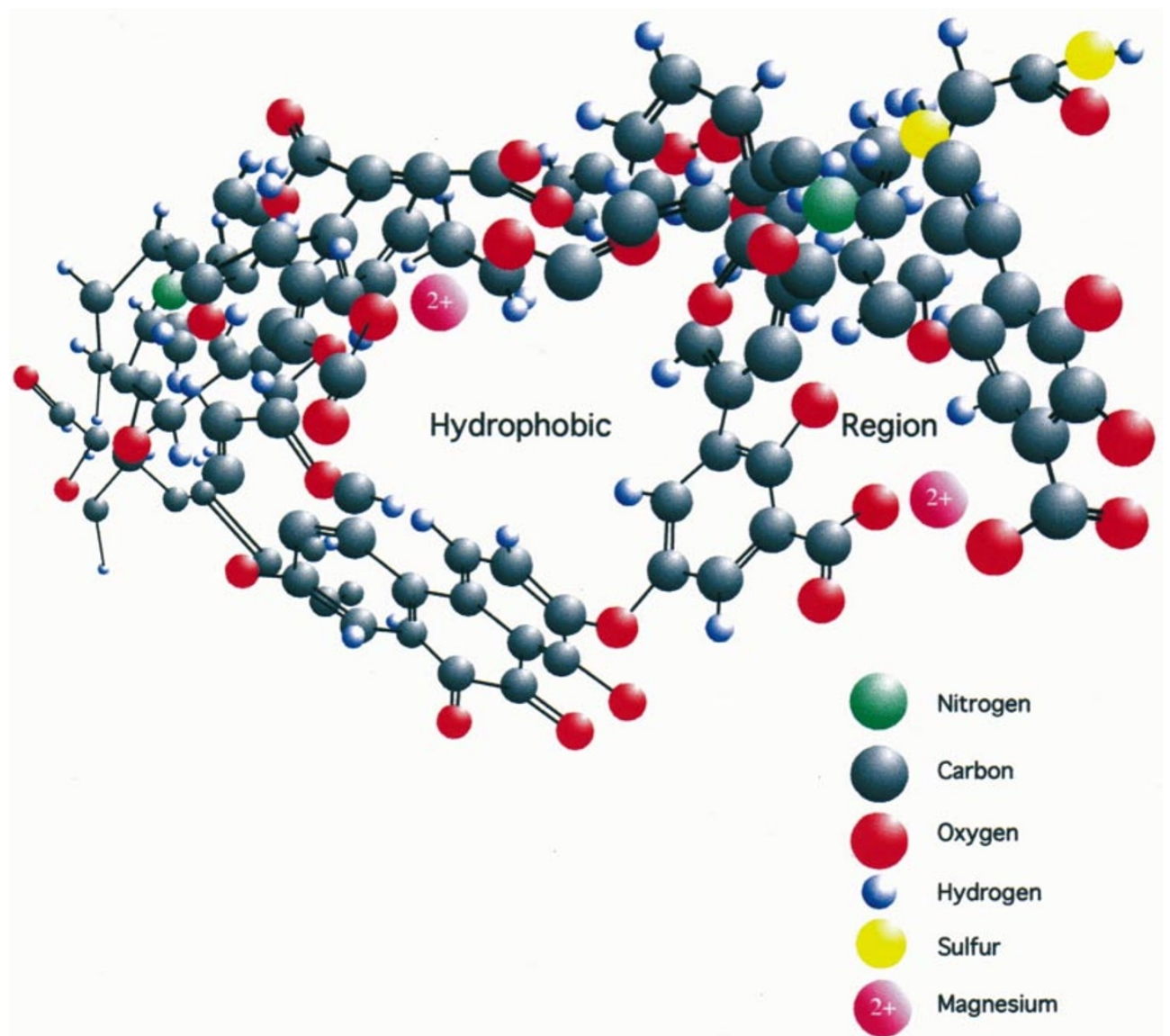

Fig. 2 Portion of the proposed "type" structure of humic acid (adapted from ref. 26, with permission).

The influence of metal ions

It was noted above that HAs are excellent ligands for metal ions in solution. Apart from being an important characteristic in its own right - for metal storage and transport - this also has a major influence on the detergent character of humics. Investigations of this behavior were prompted by the observation that HA solutions flocculate when the ionic strength is raised. This suggests the possibility that aggregation of humic polymers proceeds in a continuous fashion-from micelle-like assemblies to macroscopic precipitates - as the salt concentration is increased. It was shown through fluorescence, surface tension, and probe mobility studies that this is indeed the case. ${ }^{28,35-37}$ The evidence indicates that aqueous HAs become more effective detergents in the presence of salts, and that this

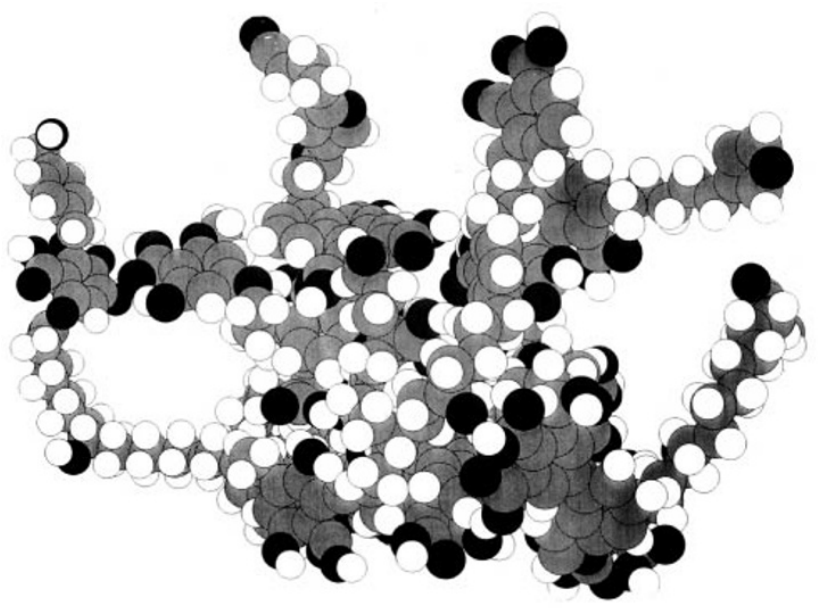

Fig. 3 Computer generated model of humic acid (from ref. 32, with permission). is entirely predicated on the nature of the cation. Thus it was found that mono-, di-, and trivalent metal ions are progressively more effective in enhancing HA detergency in solution. From the perspective of the pseudomicellar model, this was ascribed to a combination of HA charge neutralization and functional group bridging by the cations. The former refers to the fact that dissolved HA molecules bear significant negative charges, which prevent both intra- and intermolecular association. Partial neutralization by cationic species in solution circumvents this, allowing coiling and folding of the polymer. In addition, multivalent cations can augment the effect by undergoing bridging interactions with carboxy and hydroxy groups on adjacent chains. This leads to the establishment, or enhancement, of pseudomicellar domains in HA molecules, and hence to an increased detergent effect. The experimental findings leading to this model can be summarized as follows: (i) the fluorescence of a probe such as pyrene, placed into a HA solution, increases when metal ions are added, because it is sequestered in pseudomicellar HA

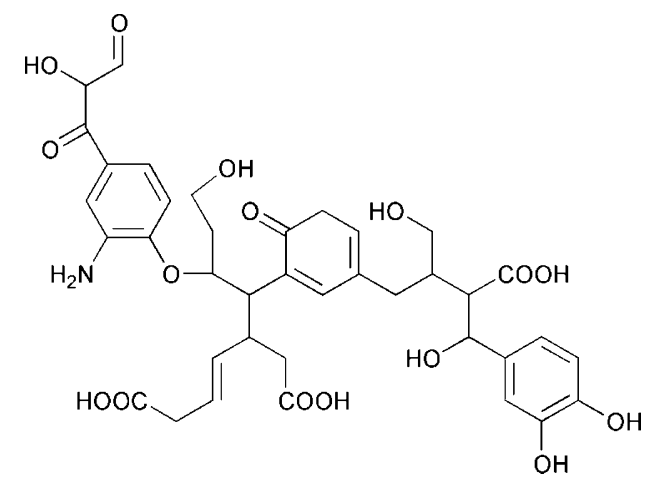

Fig. 4 The Steelink model of the humic acid monomer.

Geochem. Trans., 2000, 2 
structures and protected from quenching encounters with solution borne species; (ii) the surface tension of HA solutions increases when metal ions are added, as the amphiphilic HA molecules - initially accumulated at the air-water interface partition away from the surface when they aggregate to form pseudomicelles; (iii) the mobility of pyrene in aqueous HA especially its evaporation into a stream of nitrogen when this is bubbled through the solution, is greatly reduced by the addition of metal ions, as the humic pseudomicelles isolate the probe from the aqueous bulk.

The details of these arguments can be found in the references quoted. Fig. 2 features two divalent cations $\left(\mathrm{Mg}^{2+}\right.$ in this case) engaged in bridging interactions with HA polymer chains, illustrating their role in the formation of internal hydrophobic domains. Progressive HA aggregation through the addition of a metal ion is visualized in Fig. 5.

\section{Kinetics}

The kinetics of metal-HA associations were found to have an interesting effect on the development of HA detergency. It has been recognized that the interactions between HAs and mineral surfaces reach equilibrium relatively slowly and involve migration of metal ions within the humic structure. ${ }^{38,39}$ In analogy with this, a similar mechanism was invoked for the association of metal ions with dissolved HA. ${ }^{40}$ While, as noted above, the fluorescence of pyrene containing HA solutions increased when metal ions were added, this effect gradually diminished with time, and the emission intensities returned to their original values after periods extending from hours to days (Fig. 6).

After elimination of possible trivial causes, it was concluded that this effect was most likely due to slow changes in HA configuration after the addition of salts. The proposed mechanism involves an interaction between metal ions and anionic humic entities that is initially entirely coulombic in nature. This leads to the enhancement of pseudomicellar domains in the humic polymers, and hence to increased probe sequestration. Over time, however, the metal ions move and find their thermodynamically preferred locations within the humic structure. Interactions there are likely to involve the formation of inner sphere complexes between the metals and the humic ligands. One consequence of this is that the enhanced pseudomicelles disintegrate again, leaving the probe molecules in a situation comparable to the one that existed before the metal ions were added. Enhanced pseudomicelle formation should therefore be looked upon as a transitory state into which dissolved HAs enter when they encounter metal ions. After a variable length of time, however, the systems relax, and the detergent character of the humic polymers returns to the original level.

\section{Effect of pH}

Lowering the $\mathrm{pH}$ of aqueous HA solutions has an effect similar to adding metal salts, albeit in a less pronounced manner. ${ }^{27}$ Increasing the $\mathrm{H}^{+}$concentration causes the protonation of the HA carboxy groups, which eventually leads to precipitationthis usually begins at $\mathrm{pH} \sim 3-2$ and reaches completion at $\mathrm{pH}$ $\sim 2-1$. This should again be thought of as a continuous process, which begins at an intramolecular level, proceeds

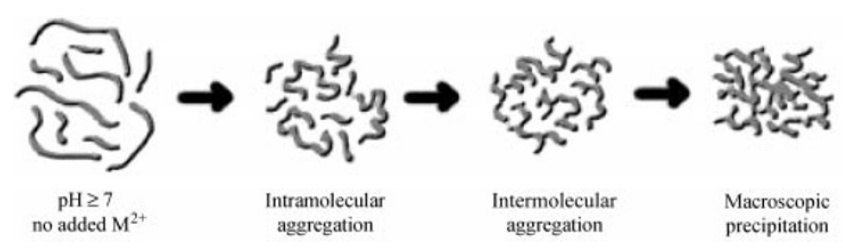

Fig. 5 Visualization of HA aggregation through continued addition of a metal ion, $\mathrm{M}^{2+}$

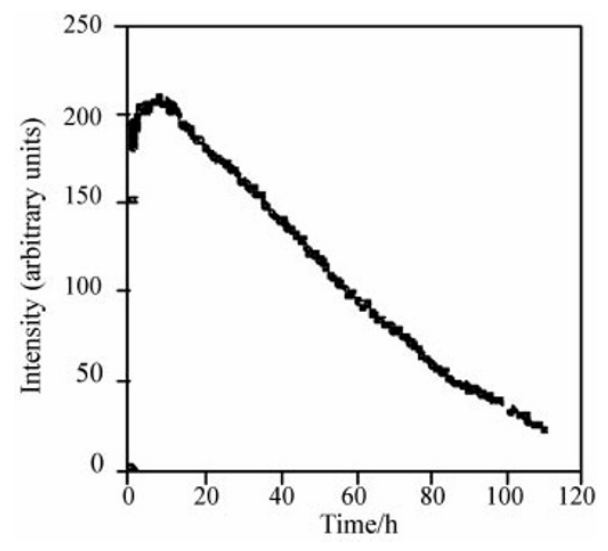

Fig. 6 Change in pyrene fluorescence intensity in a $10 \mathrm{ppm} \mathrm{HA}$ solution containing $1.0 \times 10^{-7} \mathrm{M}$ pyrene, after $\mathrm{MgCl}_{2}$ addition to a $\mathrm{Mg}^{2+}$ concentration of $3.33 \times 10^{-5} \mathrm{M}$ (adapted from ref. 38, with permission).

through intermolecular aggregation, and ultimately produces a precipitate. As it promotes aggregation at the molecular level in its earlier stages, the process again enhances the detergent character of the HAs, through the establishment of hydrophobic domains. As with metal induced micellization, this promotes the sequestration of species such as pyrene, which are eventually carried down with the precipitate.

\section{Clouding}

An interesting corollary to HA aggregation caused by cations, is the clouding that occurs when the solutions are heated. Clouding is a phenomenon familiar from surface chemistry: nonionic surfactants, especially those with polyoxyethylene (POE) hydrophilic moieties, display an inverse temperaturesolubility relationship. When their aqueous solutions are heated to a characteristic temperature known as the cloud point, phase separation is observed. In this, the solutions first turn cloudy, and then separate into a surfactant-rich and a surfactant-poor (aqueous) layer. ${ }^{39}$ This occurs because the relative permittivity of water decreases sharply with temperature, leading to reduced hydration of the POE chains. Similar behavior was observed with HA solutions that were partially neutralized by the addition of metal ions. ${ }^{26}$ When heated, they, too, underwent clouding, forming a black colloidal precipitate that eventually coagulated. Again, a pseudomicellar aggregation mechanism provides a consistent explanation for this observation.

\section{An alternative HA model}

In recent years, a dissenting view on HA configuration has surfaced, giving rise to a minor controversy in the field. In this model, conceived by A. Piccolo and co-workers, ${ }^{41-45} \mathrm{HA}$ is considered not to consist of long polymer chains, but rather of small units that are held together by weak intermolecular forces. In principle, this appears to be akin to the associative model, and it may even be argued that the idea was implicit in Wershaw's original suggestion that HA molecules associate to form micelles in aqueous solution. However, the stipulation that the aggregated species be small in size was not made in that model, and subsequent developments of the idea generally retained the polymer concept. ${ }^{46}$ The argument for the smallHA model is largely based on low- and high-pressure size exclusion chromatography (SEC). All SEC traces of HAs show a continuous size distribution from the totally excluded peak downward, with the maximum located at the predominant size range of the HA in question. Treatment of humic solutions with acetic acid was found to cause a reversible shift of this maximum to smaller sizes, and this is interpreted as an 
indication of the existence of loosely bound humic subunits Further work along these lines includes SEC separations of HAs using different mobile phases. ${ }^{42}$ These were aqueous solvents of constant ionic strength, but containing smal amounts of methanol, or acetic acid, or $\mathrm{HCl}$. They produced different apparent size distributions with the same HAs, which was again ascribed to solute deaggregation. It is noteworthy that the concentrations of methanol and acetic acid used were extremely low-in the order of $5 \times 10^{-7} \mathrm{M}$. UV hypochromism was also invoked to lend support to the small-HA concept. UV detector peak heights were found to be lower in the cases where elution volumes were greater (i.e. the fragments smaller), and this was ascribed to a deaggregation of functional groups leading to a lower absorptivity of the compounds in question. This concept is familiar from biological chemistry were hyperchromism due to aggregation (greater proximity between chromophores), and hypochromism due to the converse, are frequently encountered.

The arguments in favor of the small-HA model are compelling, but by no means irrefutable. Questions remain about other observations that are difficult to reconcile with the model. There is, for instance, the matter of the anionic nature of HAs and their progressive aggregation with decreasing $\mathrm{pH}$ or increasing metal ion concentrations (vide supra). In basic solution, HAs are polyanionic and should be expected to dissociate due to like-charge repulsion among the proposed subunits. It is difficult to imagine that such species would tenaciously hang together under such conditions. Yet, anion association is implicitly assumed by the small-HA model, when higher-pH eluents produce larger sizes than low $\mathrm{pH}$ eluents in SEC. The polymer model seems more reasonable in proposing that HA molecules "stretch out" due to internal coulombic interactions at high $\mathrm{pH}$, becoming effectively larger, and eluting more quickly. Furthermore, macroscopic aggregation of HAs at low pH is an undeniable fact. As explained above, the polymer model suggests that this is the result of progressive association that occurs when the $\mathrm{pH}$ is lowered. In other words, when the $\mathrm{pH}$ of a HA solution is slowly dropped from e.g. 10 to 2 , the molecules initially coil and fold as the negative charges are neutralized and water is eliminated. This progresses from an intra- to an intermolecular process, eventually leading to precipitation (cf. Fig. 4). The small-HA model, on the other hand, suggests that the apparent size reduction is not due to tightening of the polymer coils, but to deaggregation. This implies that there is a reversal in the (de)aggregation mechanism at some point during the lowering of the $\mathrm{pH}$ first the aggregates dissociate, and then the process reverses direction and they precipitate. This appears to be counterintuitive.

Despite these objections, however, the small-HA model should not be dismissed. The basic premise of HA aggregation appears in all models; differences of opinion exist only about the sizes of the units that aggregate. It would undoubtedly be wise for other workers in the field to revisit this matter and take another careful look at the size distribution of HAs under different solution conditions.

\section{Pollution remediation}

The propensity of HA to complex metal ions and sequester organic molecules suggests that it may be used to remove contaminants from polluted water. This has been recognized in various studies, ${ }^{47-50}$ and is the subject of a patent by Zanin and Boetti, who report the use of extracted HA for the removal of heavy metals, chlorinated organics, phosphorus, and nitrogen from waste water. ${ }^{51}$ The main difficulty in using HAs for this purpose, however, is that their isolation from natural matrices (usually soil) is laborious, time consuming, and costly. One exception to this is leonardite humic acid (LHA), which is available in bulk and requires little or no further treatment.
LHA is a material found in association with leonardite, a lignite distributed in vast deposits across North America. LHA is itself mined, and can be obtained at a purity of $c a .80 \%$, the remainder being mostly mineral matter. It presently enjoys wide use as an agricultural soil conditioner. ${ }^{52}$ It has been shown that unrefined LHA can be used for treatment of polluted water, either by a batch process, or (more conveniently) by continuous column extraction. ${ }^{53}$ Heavy metals, including $\mathrm{Pb}^{2+}$, $\mathrm{Zn}^{2+}, \mathrm{Ni}^{2+}, \mathrm{Cu}^{2+}, \mathrm{Cd}^{2+}$, and $\mathrm{Ag}^{+}$, were successfully removed, as were the organic compounds pyrene (hydrophobic), difenzoquat (a herbicide of intermediate hydrophobicity), and rhodamine B base (relatively hydrophilic). Column capacities were $0.15-2.2 \mathrm{mg} \mathrm{g}^{-1}$ LHA for the metals, and 5.4-29.0 $\mu \mathrm{mol} \mathrm{g}^{-1}$ LHA for the organic compounds. Some of the advantages of LHA for this type of application (especially in column treatment) are its low cost, its combustibility (for possible incineration of spent extractant), and its resistance to acids. This last point is especially noteworthy, since synthetic extractants often fare poorly in acid environments. Yet, metal polluted waters are frequently acidic, as exemplified by mine run-off and accumulated mine waters such as those found at the Berkeley Pit Superfund site in Butte, Montana. Acidity is in fact an enabling factor for extraction with LHA, since a low $\mathrm{pH}$ reduces its solubility to a negligible value.

Metal extraction with packed LHA columns does, however, require further development before it can be applied in large scale treatment. One of the problems encountered concerns the permeability/wettability of the humic packing. The crude LHA product has a fine grain size, with particle diameters in the range $0.1-0.6 \mathrm{~mm}$, and a specific gravity of 0.78 . The density of the bed created by this material inhibits permeability under gravity flow, leading to slow elution and channeling. In addition, the integrity of the packing is compromised by the fact that it tends to float on the eluting water. Improvements have been achieved by mixing the LHA with sea sand, but further work is needed to make deeper extractant beds and greater water flow rates possible. This problem is presently being studied in the author's laboratory.

\section{References}

1 E. A Paul, C. A Campbell, C. A. Rennie and K. J. McCallum, Investigations of the dynamics of soil humus, utilizing carbondating techniques, Trans. 8th Intern. Congr. Soil Sci., 1964, 3, 201.

2 K. A. Thorn, D. W. Folan and P. MacCarthy, Characterization of the International Humic Substances Society Standard and Reference Fulvic and Humic Acids by Solution State Carbon-13 and Hydrogen-1 Nuclear Magnetic Resonance Spectrometry, Water Resources Investigations Report 89-4196, US Geological Survey, Denver, CO, 1989.

3 F. J. Stevenson, Humus Chemistry, 2nd edn., John Wiley Sons, Inc., New York, 1994, p. 46.

4 C. Steelink, Elemental Characteristics of Humic Substances, in Humic Substances in Soil, Sediment, and Water, ed. G. R. Aiken, D. M. McKnight, R. L. Wershaw and P. MacCarthy, John Wiley, New York, 1985, pp. 457-476.

5 Aquatic Humic Substances-Influence on Fate and Treatment of Pollutants, ed. I. H. Suffet and P. MacCarthy, Advances in Chemistry Series 219, American Chemical Society, Washington, DC, 1989.

6 Humic Substances II-In Search of Structure, ed. M. H. B. Hayes, P. MacCarthy, R. L. Malcolm and R. S. Swift, John Wiley Sons, New York, 1989

7 Humic Substances and Organic Matter in Soil and Water Environments, ed. C. E. Clapp, M. H. B. Hayes, N. Senesi and S.M. Griffith, International Humic Substances Society, St. Paul, MN, 1996.

8 F. J. Stevenson, Humus Chemistry: Genesis, Composition, Reactions, 2nd edn., John Wiley Sons, New York, 1994

9 Humic Substances: Structures, Properties, and Uses, ed. G. Davies and E. A. Ghabbour, Royal Society of Chemistry, Cambridge, UK, 1998.

10 Humic Substances: Advanced Methods, Properties, and Applica- 
tions, ed. G. Davies and E. A. Ghabbour, Royal Society of Chemistry, Cambridge, UK, 1999.

11 Perspectives in Environmental Chemistry, ed. D. L. Macalady, Oxford University Press, Oxford, UK, 1998.

12 J. Buffle, Complexation Reactions in Aquatic Systems: An Analytical Approach, Ellis Horwood Ltd., New York, 1990.

13 N. Senesi, Metal-Humic Substance Complexes in the Environment. Molecular and Mechanistic Aspects by Multiple Spectroscopic Approach, in Biogeochemistry of Trace Metals, ed. D.C. Adriano, Z.-S. Chen, S.-S. Yang and I. K. Iskandar, 1993 Science Reviews Ltd., Northwood, UK, pp. 429-495.

14 C. T. Chiou, P. E. Porter and D. W. Schmedding, Partition equilibria of nonionic organic compounds between soil organic matter and water, Environ. Sci. Technol., 1983, 17, 227.

15 Y. P. Chin and W. J. Weber, Jr., Estimating the effects of dispersed organic polymers on the sorption of contaminants by natura solids. I. A predictive thermodynamic humic substance-organic solute interaction model, Environ. Sci. Technol., 1989, 23, 978.

16 A. Fredenslund, J. Gmehling and J. Rasmussen, Vapor-Liquid Equilibria Using UNIFAC, Elsevier Scientific, New York, 1977.

17 T. T. Ames and E. A. Grulke, Group contribution method for predicting equilibria of nonionic organic compounds between soil organic matter and water, Environ. Sci. Technol., 1995, 29, 2273

18 J. F. McCarthy and B. D. Jimenez, Interactions between polycyclic aromatic hydrocarbons and dissolved humic material: binding and dissociation, Environ. Sci. Technol., 1985, 19, 1072.

19 D.-Y. Lee and W. J. Farmer, Dissolved organic matter interaction with napropamide and four other nonionic pesticides, J. Environ. Oual., 1989, 18, 468 .

20 C. E. Clapp, U. Mingelgrin, R. Liu, H. Zang and M. H. B. Hayes, A quantitative estimation of the complexation of small organic molecules with soluble humic acids, J. Environ. Qual., 1997, 26, 1277

21 W. Rochus and S. Sipos, Micelle formation by humic substances, Agrochimica, 1978, 22, 446.

22 R. L. Wershaw, A new model for humic materials and their interactions with hydrophobic organic chemicals in soil-water or sediment-water systems, J. Contam. Hydrol., 1986, 1, 29.

23 R. L. Wershaw, Membrane-micelle model for humus in soils and sediments and its relation to humification, U.S. Geological Survey, Denver, Open file report 91-513, 1992.

24 R. L. Wershaw, Model for humus in soils and sediments, Environ Sci. Technol., 1993, 27(5), 814.

25 M. Tschapek and C. Wasowski, Humic acid: its adsorption at the water/benzene interface, Agrochim., 1984, 28, 1.

26 R. R. Engebretson and R. von Wandruszka, Microorganization in dissolved humic acids, Environ. Sci. Technol., 1994, 28(11), 1934

27 R. R. Engebretson, T. Amos and R. von Wandruszka Quantitative approach to humic acid associations, Environ. Sci. Technol., 1996, 30(3), 390.

28 R. von Wandruszka, The micellar model of humic acid: evidence from pyrene fluorescence measurements, Soil Sci., 1998, 163(12) 921.

29 R. R. Engebretson and R. von Wandruszka, The effect of molecular size on humic acid associations, Org. Geochem., 1997, 26, 759 .

30 R. von Wandruszka, M. Schimpf, M. Hill and R. R. Engebretson, Characterization of humic acid size fractions by SEC and MALS, Org. Geochem., 1999, 30, 229.

31 H.-R. Schulten and M. Schnitzer, Three-dimensional models for humic acids and soil organic matter, Naturwissenschaften, 1995 , 82, 487.

32 H.-R. Schulten, The three-dimensional structure of humic substances and soil organic matter studied by computational analytical chemistry, Fresenius' J. Anal. Chem., 1995, 351, 62.

33 G. Davies, A. Fataftah, A. Cherkasskiy, E. A. Ghabbour, A. Radwan, S. A. Jansen, M. D. Paciolla, L. T. Sein, Jr. W. Buermann, M. Balasubramanian, J. Budnick and B. Xing,
Tight metal binding by humic acids and its role in biomineralization, J. Chem. Soc,. Dalton Trans., 1997, 4047.

34 L. T. Sein, Jr., J. M. Varnum and S. A. Jansen, Conformational modeling of a new building block of humic acid: approaches to the lowest energy conformer, Environ. Sci. Technol., 1999, 33, 546.

35 C. Ragle, R. R. Engebretson and R. von Wandruszka, The sequestration of dissolved micropollutants by dissolved humic acids, 1997, Soil Sci., 1997, 162, 106.

36 L. M. Yates, R. R. Engebretson, T. M. Haakenson and R. von Wandruszka, Immobilization of aqueous pyrene by dissolved humic acid, Anal. Chim. Acta, 1997, 356, 295.

37 R. von Wandruszka, C. Ragle and R. R. Engebretson, The role of selected cations in the formation of pseudomicelles in aqueous humic acid, Talanta, 1997, 44, 805 .

38 O. Wahlberg and A. Staffan, Studies of humic and fulvic acids I. Determination of the steady states for slow processes in $0.1 \mathrm{M}$ $\mathrm{NaCl}$ aqueous solution at $25^{\circ} \mathrm{C}$, Acta Chem. Scand., 1996, 50(7), 561.

39 J. Skopp, Analysis of time-dependent chemical processes in soils, J. Environ. Qual., 1986, 15(3), 205.

40 R. R. Engebretson and R. von Wandruszka, Kinetic aspects of cation-enhanced aggregation in aqueous humic acids, Environ. Sci. Technol., 1998, 32, 488 .

41 W. L Hinze and E. Pramauro, A critical review of surfactantmediated phase separations (cloud point extractions): theory and applications, Crit. Rev. Anal. Chem., 1993, 24, 133.

42 A. Piccolo, S. Nardi and G. Concheri, Micelle-like conformation of humic substances as revealed by size-exclusion chromatography, Chemosphere, 1996, 33, 595.

43 A. Piccolo, S. Nardi and G. Concheri, Macromolecular changes of soil humic substances induced by interactions with organic acids, Eur. J. Soil Sci., 1996, 47, 319

44 P. Conte and A. Piccolo, High pressure size exclusion chromatography (HPSEC) of humic substances. Molecular sizes, analytica parameters, and columns performance, Chemosphere, 1998, 38 517.

45 P. Conte and A. Piccolo, Conformational arrangement of dissolved humic substances. Influence of solution composition on association of humic molecules, Environ. Sci. Technol., 1999, 33, 1682 .

46 R. L. Wershaw and K. R. Kennedy, in Humic substances Structures, Properties and Uses, 1998, ed. G. Davies and E. A. Ghabbour, The Royal Society of Chemistry, Cambridge, UK, pp. 61-68.

47 J. J. Alberts, C. Griffin, K. Gwynne and G. J. Leversee, Binding of natural humic matter to polycyclic aromatic hydrocarbons in rivers of the southeastern United States, Wat. Sci. Tech., 1994 30(10), 199

48 H. Xu, S. Lesage, L. Durham and K. Novakowski, The use of humic acids to enhance the removal of aromatic hydrocarbons from aquifers contaminated with petroleum products. Part I Laboratory studies, In Proceedings of fourth annual symposium on groundwater and soil remediation, 1994, Calgary, Alberta, pp. 635646.

49 S. Lesage, H. Xu, K. Novakowski, S. Brown and L. Durham, Use of humic acids to enhance the removal of aromatic hydrocarbons from contaminated aquifers. Part II: Pilot scale, in Proceedings of fifth annual symposium on groundwater and soil remediation, 1995 , Toronto, Ontario, compact disk.

50 M. Rebhun, S. Meir and Y. Laor, Using dissolved humic acids to remove hydrophobic contaminants from water by complexationflocculation process, Environ. Sci. Technol., 1998, 32, 981.

51 M. R. Zanin and T. G. Boetti, Method and related product for purification of waste water, US Patent 5,415,778, May 16, 1995

52 Horizon Ag-Products, Product Guide, distributed by Horizon AgProducts, 318 North Neel Street, Kennewick, WA 99336, USA.

53 L. M. Yates and R. von Wandruszka, Decontamination of polluted water by treatment with a crude humic acid blend, Environ. Sci. Technol., 1999, 33, 2076. 